\title{
A Quest for Knowledge Representation Instruction
}

\author{
Lisa Orszullok $^{1}$ Kathrin Knautz $^{1}$ Simone Soubusta $^{1}$ \\ ${ }^{1}$ Department of Information Science, Heinrich-Heine University Dusseldorf, Germany
}

\begin{abstract}
Given the evidence for a new generation of users - the digital natives, an examination of the factors that impact upon their social and learning behavior, seems warranted. In addition to these changes in learning habits, we should pose the question whether this generation lacks a new form of teaching to meet their needs. We therefore designed a concept for a course using game-based learning elements to improve students' information literacy in knowledge representation.
\end{abstract}

Keywords: flow, gamification, gamebased learning, information literacy

\section{Digital Natives \& the Knowledge Society}

In this paper we shall examine the learning behavior of digital natives and focus on the issue of how they can be taught information literacy. To answer this question, we begin by taking a closer look at the characteristics of digital natives. The traits of a digital native do not only affect the online environment but also their social life and their learning and study habits [1].

Born into a digital world and having grown up in an environment dominated by technology, the digital natives are inured to obtaining their desired information whenever and wherever they require them. This is caused by the fact that mobile phones - especially smartphones - , laptops, the Internet and so forth are integral parts of their everyday life [2]. The new generation does not only have an excellent and permanent access to information, but is also connected to friends and acquaintances all over the world 24/7. Moreover they stand out in terms of their multitasking skills. Handling a lot of information and social software on time there is an increased requirement for the ability to cope with several tasks simultaneously, which has been nearly perfectly adopted by the young grown-ups.

To go into detail this generation likes to be challenged e.g. to discover information and to improve their state of knowledge in the form of interaction with fellow students. On account of that they have a high interest in computer games which additionally offer them the possibility to exchange with others [2].

What does this mean for their learning behavior and which effects does it have on didactics and educational systems? We can state that "today's students are no longer the people our educational system was designed to teach" [1]. Because of their massive interaction with new media the students get easily bored by the traditional teaching methods [3]. Keeping the traits of the digital natives in mind, we can assume that teamwork and challenging tasks in which they can creatively find their own ways to the answer would fit the needs of the new generation. They are not interested in ex-cathedra teaching where the approach is predetermined. Instead, they have a great desire to explore the procedure of finding a solution on their own in collaboration with their fellow students [2]. 
As a part of the knowledge society the digital natives take up an important role because they have a high affinity concerning information and communication technology (ICT). Growing up in a digitally and technologically well-appointed world entails that this generation has a readiness of mind when handling new technologies and online offers. Granted, the ICT infrastructure and the correct ways of coping with it are significant elements, but as a person in a knowledge society we nevertheless have to be information literate and the aims of information literacy go far beyond ICT skills. Information literacy includes search competency, the ability to represent knowledge, as well as social, ethical and legal awareness of dealing with information. Even if information literacy is gaining importance on an academic and political level, there is still a lack of corresponding didactic offers [4].

\section{Gamification in an Educational En- vironment}

Regarding this new generation and its desires, we designed a complete concept for knowledge representation instruction based on game elements in cooperation with a group of Master students [5]. The corresponding lecture to this concept is an inherent part of the curriculum for the second semester Bachelor students of our Information Science and Language Technology. In this lecture they learn how to use knowledge bases like thesauri, classifications or ontologies, how to index documents with them and how to write abstracts. The lecture focuses furthermore on the development, upgrading and support of such knowledge bases.

The whole concept is embedded in an epic story. This story is divided into four acts, each consisting of four quest lines for the given 22 topics of knowledge rep- resentation which were spread equally over the different parts: In the beginning the 16 involved students who worked in pairs started with a fourfold allocation of each story thread. But in the course of the project it became apparent that such a high number of allocations was not necessary to meet a certain standard. Instead, each quest line was only assigned to two groups. Owing to the high motivation of the students, the resulting tasks were of high quality leading in some acts to diverse versions of the story, where the decision of the student influences how the story continues. In order to offer the students enough room to develop their own ideas, we provided only a little information concerning the basic outline of each act. In this way the design process was very dynamic. To ensure that the project and the creativity of the students did not totally go off course we used storyboarding methods [6][7]. This helped keep track of the project development and guaranteed that the concept matches with the preexisting lecture of knowledge representation.

The use of game mechanics is inspired by the fact that "games represent an informal learning environment" which is based on the great diversity of available content types. In this environment the students have space to learn actively, experientially and with a focus on specific problems. By this means the student does not only study subject matters, but he experiences them. The total involvement in the learning process facilitates engagement, enjoyment and effectiveness [8]. Similar projects with game-based learning elements have already shown that the concept of a gamified course is successful in terms of motivation and learning outcomes. Examples are Quest to Learn (q21) and the Khan Academy. Quest to Learn is a public school in New York City based on an innovative learning community. The whole curriculum is "a translation of 
the underlying form of games into a powerful pedagogical model" [9]. Another instance of gamification in education is the Khan Academy which is a platform for interested user all over the world to use interactive and multimedia subject matters. Therefore there is a combination of educational videos and tasks with individual adapted degrees of difficulty [10]. The investigation of Marina Papastergiou authenticates that digital game-based learning is more effective in promoting students' knowledge and their enjoyment and their interest in comparison to nongaming learning environments [11]. You can also find models for gamification in the university context. The most popular example is the concept of Lee Sheldon who organizes his seminars as multiplayer games. The students must solve quests and collect experience points to complete the course. The feedback of the students and the examination performance show that the concept has a positive impact on the learning behavior [12]. Ebner und Holzinger show similar results concerning the fun factor and the enjoyment of learning [13]. They designed an online game for a German Master course of civil engineering.

\section{Results}

The concept for this gamified instruction in knowledge representation is divided into two parts:

First, there is an online platform on which the students can do obligatory exercises. Here they can learn at their own pace and check their current level of knowledge independently of time and location. Furthermore, there are additional exercises for students to deepen and improve their comprehension of the various lecture topics. All tasks are designed in such a way that if the student fails a task he can repeat it again and again until he passes it. In addition to this, most of the tasks are created in such a manner that the students immediately get a feedback of their work. Similarly to a computer game they have to retry the exercise if they slip up. By using drag-and-drop, multiple choice questions, cloze and so forth, the student encounters different task types with immediate feedback. In order to provide a broad variety of tasks there are also exercises where the students have to write a short text on a specific topic and hand it in. These submissions are corrected by tutors, thus there is a time-delayed acknowledgement. Nevertheless, the great breadth of tasks has the advantage that it increases the variation and results in a better concentration while also avoiding monotonousness.

Furthermore, the platform offers several individual settings to personalize the account. Thus the participant has, for example, the possibility to set up an avatar according to their own preferences. This increases the identification with the ingame character and boosts the affiliation to the platform.

But the concept is not only based on the platform. It is accompanied by a specially structured classroom course where the students can ask questions and work in teams on exercises. This course also integrates game-based elements. There are, for instance, tasks where the students compete in informative games to demonstrate their knowledge. Another example is that the students get ambitious tasks which they have to solve in a permanent study group (guild) or in spontaneously formed groups. Both team conceptions also exist on the platform - the students can become a part of a guild to "fight" together as well as support each other and they can also build so-called pick up groups to solve a problem. 


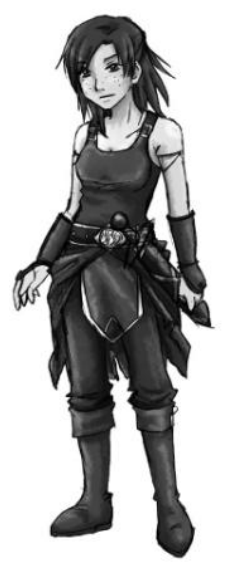

Fig. 1: In-game characters can be designed as requested by the participant regarding gender and race (e.g. human and orc).

Similarly to computer games the "player" can level up his character by experiencing the story and fulfilling quests. The more points he earns and the higher his level is the more challenging the tasks are. Besides the leveling system, there are more game elements realized. The participants receive experience points and achievements which provide feedback on what they have achieved. Moreover, those essential elements help the students with error recognition and provide them at any time with a clear overview of their skills and strengths as well as of their weaknesses.

Using a predefined score, we can clearly establish when a student successfully passes the knowledge representation course (cf. Fig. 2). But at this point the adventure is not over. If the student is interested in going on with the story and the quests there is an incentive and a special treat for him: he can gain a bonus for his final examination in the curricular module if he completes almost all quest lines and side quests.

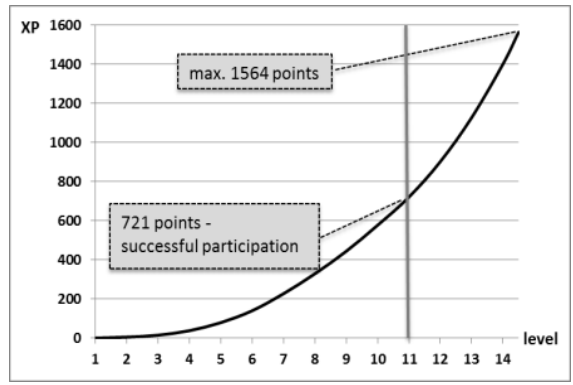

Fig. 2: Allocation of the points distributed to the level system

With the large offer of tasks and the possibility to repeat them at any time, the students obtain a good preparation for the exam. In combination with the enthralling story we hope that the students do not practice because they have to, but owing to interest and enjoyment of learning.

\section{Outlook}

The project has been announced to the second semester students and will be put into practice for the very first time in the summer semester 2013. In preparation for this implementation we conducted a survey in which we tried to determine the students' general attitude towards games and what they think about gamification in the context of university didactics in particular. Our first finding was that almost every student is a gamer of some kind (i.e. including not only video games, but also board games etc.). To quantify this statement, approximately $90 \%$ of the students in the academic year play games. Further reactions of the students show that most of them are interested in the project and think that it is rather an exciting and worthwhile idea to rework the existing didactical model. But we must also mention that around $30 \%$ of the polled students have a critical attitude towards the concept of game-based learning. They are insecure concerning the profitability and suspect that this would not be didactically 
valuable for them. Needless to say that the students are free to choose whether to participate in the project or to opt for the traditional model including teachercentered teaching. But one of our aspirations is to convince students that learning does not have to be dry and unamusing. The projected evaluation during the semester and afterwards will offer valuable clues as to whether the concept catches on and whether the study motivation and results improve or not.

The aim of the project is not to replace traditional concepts but to supplement them with innovative technological possibilities. Therefore the online platform is just as important as the in-class lecture they complement another.

Nonetheless, it is obvious that a change in our didactical methods is necessary to fit the needs of the digital natives in order to increase motivation to learn and, furthermore, that they take delight in it. At least the enjoyment of learning is essentially deep-seated in everybody, because learning and playing are by nature closely connected. This is, for example, evidenced by the fact that, in the earliest adolescence, learning coincides with playing [14]. So we are game for some new ideas and concepts to motivate the digital natives and to return fun to our classrooms.

\section{References}

[1] M. Prensky, "Digital natives, digital immigrants", In On The Horizon, 9(5), 2003.

[2] J. Gaston, "Reaching and Teaching the Digital Natives", In Library Hi Tech News, 23(3), pp. 12-13, 2006.

[3] C. Artelt, J. Baumert, N. JuliusMcElvany, and J. Peschar, Learners for Life - Student Approaches to Learning, OECD, Paris, 2003.

[4] S. Gust von Loh, and W.G. Stock, „Informationskompetenz als
Schulfach?", In

Informationskompetenz in der Schule. Ein informationswissenschaftlicher Ansatz, pp. 1-20, 2013.

[5] G. Zichermann, and C. Cunningham, Gamification by Design, O'Reilly Media, Sebastopol, CA, USA, 2011.

[6] K. P. Jantke, and R. Knauf, "Didactic Design Through Storyboarding: Standard Concepts for Standard Tools", In Proc. of the 4th International Symposium on Information and Communication Technologies, pp. 20 $-25,2005$.

[7] K. P. Jantke, and R. Knauf, "Storyboarding for Playful Learning", In Proc. of World Conference on ELearning in Corporate, Government, Healthcare, and Higher Education, pp. 3174-3182, 2006.

[8] D. G. Oblinger, "The Next Generation of Educational Engagement", In Journal of Interactive Media in Education, 8, 2004.

[9] http://q21.org/curriculum

[10] https://www.khanacademy.org/

[11] M. Papastergiou, "Digital GameBased Learning in high school Computer Science education: Impact on educational effectiveness and student motivation", In Computers \& Education, 52, pp. 1-12, 2009.

[12] L. Sheldon, The Multiplayer Classroom, Course Technology, Boston, USA, 2012.

[13] M. Ebner, and A. Holzinger, "Successful implementation of usercentered game based learning in higher education: An example from civil engineering", In Computers \& Education, 49(3), pp. 873-890, 2007.

[14] H. Papoušek, "Experimental Studies of Appetitional Behaviour in $\mathrm{Hu}$ man Newborns and Infants", In Early Behaviour: Comparative and Developmental Approaches, pp. 249-277, 1999. 